[Livingstone, I. (2003). Going, Going ...? Men in Primary Teaching In New Zealand. New Zealand Annual Review of Education, 12, 39-74]

\section{Going, Going ...? Men in Primary Teaching In New Zealand}

\section{IAN LIVINGSTONE}

\begin{abstract}
:
This article examines the issue of the declining numbers of men in primary teaching, and charts the points in their preparation, induction and classroom experience where attrition may have occurred. Some reasons are suggested, based upon research evidence. It concludes with four arguments for having more men in the classroom, which are classified as: academic, social, environmental, and representational. Of these the representational aroument is regarded as the most compelling. Primary school staff should be more representative of society at large, conveying the message that learning and academic achievement are for everyone.
\end{abstract}

$\mathrm{O}$ ver the last few decades in New Zealand, gender issues in primary teaching have not figured largely in major research studies, and where they are mentioned, the emphasis has been on the position of women in teaching, rather than men. Women have been seen to be the ones suffering a variety of forms of disadvantage, particularly in their restricted promotion possibilities.

But at the end of the 20th century, men's issues have become much more salient in primary education, for a number of reasons. Perhaps the most obvious of these is the declining numbers of men in primary classrooms, in many countries, or at least their declining proportions in comparison to women. This is a world-wide phenomenon, from which New Zealand has not been exempt. Internationally, in 1999, men made up only 23 percent of the primary teaching workforce across 23 OECD countries for which data were available (OECD, 2001, Table D2.2). Percentages of males among teaching staff in public and private primary education ranged widely from a high of 40 percent in Luxembourg down to a low of only 5 percent in Italy. The New Zealand
40 Ian Livingstone

figure cited was 18 percent; corresponding figures for other Englishspeaking countries were Canada (32\%), the United Kingdom $(24 \%)$, Ireland (15\%), and the United States $(13 \%)$. More recent statistics from England put the figure there at just over 13 percent (DFES, 2001, cited in Bricheno \& Thornton, 2002), In 1956, 42 percent of primary school teachers in New Zealand were male, and the proportion has fallen steadily ever since (Ministry of Education, 1998). Furthermore, as in most other countries, the percentage of male primary school teachers in the 50-59 age group in 1999 was substantially higher than the percentage of women, and the percentage in the under 30 year age group correspondingly lower, 22 percent compared with 14 percent, respectively (OECD, 2001, Table D2.3). It is apparent that, given current trends, the total proportion of male teachers will continue to fall over the next decade. The trend in New Zealand over the last decade is given in more detail in Table 3 later in this article, along with some discussion of the implications.

\section{Men in Pre-Service Teacher Education \\ Entry characteristics}

The ratio of males to females in the primary division of teacher education in New Zealand is given in Table 1, for four equally-spaced years between 1992 and 2001. The figures are formal enrolments in public pre-service primary teacher education, that is, the total number of students in the system at all levels, based on a minimum number of Equivalent Full Time Student (EFTS) hours of more than 0.03 (3\%, or one week per year), and including bilingual and immersion education courses. They include students in universities and colleges of education, plus much smaller numbers in polytechnics since 1994, and wananga (Maori tertiary institutions) since 1997, but not the growing number of students in recently-established private training institutions. The figures are drawn from the July 31 returns in each year, and thus exclude students finishing or withdrawing before that date, and students starting after that date, in every year given.

The numbers of men in pre-service primary teacher education as a proportion of the total enrolment at all stages appear to be relatively stable, within the limits of normal fluctuations from year to year, at around one-fifth, with a slight drop in 1998. Although the total numbers of men are rising, so are the numbers of women, to correspond, with particularly strong growth for women between 1995 and 1998. 
Table 1 Formal enrolments in public pre-service primary teacher education, by gender

\begin{tabular}{lrrrl}
\hline & 1992 & 1995 & 1998 & 2001 \\
\hline Male & 957 & 1,197 & 1,405 & 1,675 \\
Female & 3,482 & 4,262 & 6,019 & 6,448 \\
Total & 4,439 & 5,459 & 7,424 & 8,123 \\
$\%$ male & $21.6 \%$ & $21.9 \%$ & $18.9 \%$ & $20.6 \%$ \\
$\%$ male first year & $22.1 \%$ & $21.6 \%$ & $20.5 \%$ & $21.2 \%$ \\
\hline
\end{tabular}

Source: Ministry of Education Database, 1992, 1995, 1998, 2001

But it is interesting to compare these figures with the final row in the table, giving proportions of men in the first year of their teacher education courses. These have fluctuated a little over the decade, too, but in every year except 1995 the proportions of men in their first year are higher than their proportions in the total course enrolment. Other things being equal, this suggests a slightly higher withdrawal rate from pre-service teacher education for male students over the past decade.

\section{The selection process}

In 1992, the Ministry of Education conducted a survey of applicants to teacher education programmes, based on information collected by the five colleges of education and the School of Education at the University of Waikato. It noted that, since 1990, there had been a growing number of applicants, which had increased competition to gain entry into teacher training. There had also been an increase in the proportion of male applicants, and they now made up 24.5 percent of the total (Nicholl \& Totoro, 1992, p. 47). In all, about 59 percent of the applicants reached the stage of being interviewed ( $58 \%$ men, $59 \%$ women), but only 35 percent were offered a position as a teacher trainee $(31 \%$ men, $37 \%$ women). It was in this step that the gender imbalance started to become most pronounced. To some extent it was reversed at the next stage, as 84 percent of men accepted the offer, as against 77 percent of women (p. 54). However, the authors conclude that "throughout the selection process, female applicants were more often successful than their male counterparts, tipping the gender balance even further in favour of women" (p. 50).
Perhaps the most ambitious study of pre-service teacher education in New Zealand, although now somewhat dated, was a longitudinal research project begun in 1989, conducted over four years at the New Zealand Council for Educational Research, and funded through a contract with the Ministry of Education. This study charted the attitudes and perceptions of a cohort of 549 students at three of the six colleges of education (Auckland, Wellington and Christchurch), and followed the students completely through their pre-service education experiences and out into their first positions as beginning teachers (Renwick \& Vize, 1990, 1991, 1992, 1993a, 1993b). Data were gathered from postal questionnaires, interviews and student records. Although it was carried out over a decade ago, the study was unique in that it was truly longitudinal, following the 1989 cohort for four years until 1992, and not relying on retrospective impressions gathered by staff of students from their own colleges, as most previous (and subsequent) studies in this country have been.

In what appears to have been the only New Zealand study to have considered the characteristics of those who are unsuccessful in their application to train as primary school teachers in New Zealand, the authors drew random matched samples of approximately 120 unsuccessful applicants from each of the three colleges of education in their study. Many applicants had changed addresses, but an eventual response rate of 51 percent was achieved to a postal questionnaire. It appeared that a greater proportion of males applied than were accepted; 28 percent of the respondents were male, as compared with 19 percent of those finally admitted. Younger applicants were more likely to be accepted, as were those from coeducational state schools. The majority of comments of unsuccessful applicants reflected dissatisfaction with the selection interview itself, the racial bias they perceived, or the personal rejection they felt. However, the data are historical, the response rate marginal, and subsequently the selection process has been changed, with colleges and other pre-service education institutions now responsible for selecting their own students (1991, pp. 190-92). Apart from this study, little information is available on the characteristics of men who apply for teacher education courses in New Zealand, but are not selected.

\section{Preparation for teaching}

What are we able to say about the comparative qualifications and prior experience of men and women enrolling in pre-service education, with 
the intention of becoming primary teachers in New Zealand? Very little, it would seem. Alton-Lee and Praat (2000), in their comprehensive review of gender issues in the New Zealand compulsory school sector, cite a large USA study of over 2000 pre-service and in-service male elementary teachers by Brookhart and Loadman (1996), which found that the male trainees were less academically oriented and not so well qualified on entry to teacher education as the female trainees. However, there appears to be little robust research information to substantiate this for New Zealand. There is a small amount of recent anecdotal evidence in one college of education, however, to suggest this may be the case.

Corkery (2001) interviewed two recruitment officers at Dunedin College of Education in 2000, and records (p. 9) that teaching is considered by many prospective students to be the career choice if one "does poorly" in bursary examinations. After offers of acceptance were made by Dunedin College of Education to 270 prospective full-time primary teacher trainees in late 1999 and early 2000, 48 withdrew. All but two of these were school leavers who had decided to go to university instead. Reports from these students indicated that they intended to pursue another university degree, not a teaching degree.

Corkery also reported that one-quarter of the 270 students offered places at the Dunedin College of Education in 2000 were "automatic entry". This category is based on their Year 13 grades and on references from school principals regarding their academic potential for tertiary study. None of the students so preferred were men. Further evidence was adduced by the fact that the top academic grades and scholarships awarded at the College (normally four per year) went to women in each of the four years 1997 to 2000 (p. 10).

\section{Withdrawal From Training}

In the Renwick and Vize longitudinal study, some information was provided on students who had left college in their first year, without completing their training. Included in the group were students who had resigned, but also students who had been granted leave or deferment of their studies for such reasons as: undertaking full-time university studies, maternity or sick leave, leave for other personal reasons, such as caring for dependants, and leave granted to allow them to reconsider their own suitability as primary teachers. From a series of telephone interviews, it was found out that there were two main reasons given for leaving college:
- students realised they had made the wrong career choice;

- "the course does not really prepare students for the reality of teaching" (1991, p. 189).

However, only about one-third of the students could be contacted, and in view of the possibilities of bias, no analysis by gender was undertaken.

In a small-scale survey conducted at the Christchurch College of Education in 1997, Cushman noted that of a total of 53 male and female students who withdrew from the college during their first year of primary teacher education, a disproportionate number were male. Of the total male intake, 23 percent withdrew (19 out of 81 ), compared to 9 percent for women (1998, p. 53). She found that males tended to withdraw earlier in the year, and were less affected by the timing of the first teaching practice (usually in May, when teachers spend 4-5 weeks in a classroom, for the first time).

Her results suggested that the more mature male students were the ones most likely to withdraw. The largest group of male leavers within the first year were those in the 20-25 age range, who would have had other work or educational experiences since leaving secondary school (p. 54). She hypothesised that some of them may simply be experimenting with occupational choices; others may be university graduates uncertain about what career path would best make use of their qualifications. Whatever their motivation, she observed that their decision to withdraw from a teaching career was not taken lightly, and the colleges could well examine the content of their courses, historically designed with school-leavers in mind, to see how closely they fitted adult learners (p. 54).

The three most common reasons given for withdrawal, for both male and female students, were: wrong career choice; stress outside college; and stress inside college, in that order. No other reasons figured largely, and no clear differentiation between men and women emerged in the results. As far as the first reason is concerned, Cushman wondered whether difficulties encountered in college programmes or on teaching practice may have led students to give "wrong career choice" as a more outwardly acceptable reason. They may have in fact experienced failure in the course. As the workload at college built up, students who had not anticipated the time needed for preparation, which began to intrude on their family life or outside jobs, may have come to believe that they were unsuited to the pressures of a teaching lifestyle. This is confirmed 
by the other two major reasons given. Many students were unable to cope with the workload, especially when combined with such things as university studies, families (many students were sole parents), and sports commitments. Stress, inside and outside the college, was the inevitable result. The author argued that, in view of this, colleges of education needed to revisit the structure and content of courses, and enhance support systems and pastoral care provisions.

Cushman also hypothesised that the New Zealand college of education environment may have become "feminised", with 67 percent of all college lecturers now female. Male students were thinly spread amongst professional studies groups, and there may have been an unconscious influence operating which adversely affected the progress and subsequent retention of some men (p. 54). She went on to ask, "Are colleges of education more ready to accept male applicants because of their gender, rather than their suitability?" and suggested some practical steps which might help alleviate the situation, for all students. But the answers prove elusive for the higher retention of men.

In a demographic study, drawn from computer records of the total 1997 entry cohort to the Auckland College of Education, Trembath (2000) found that, of the 301 students who were admitted to the new three-year BEd (Teaching) primary teaching programme, significantly more of the men withdrew without graduating, 38 percent as compared with 20 percent of the women (p. 20). Her findings endorse those of Cushman, and she suggests the notion of "shattering of the images" as an explanation of the reason why so many students leave in their first year of study, particularly after their first teaching practicum. This "may be the time image and reality would be most strongly in conflict" (p. 27, citing Chambers \& Roper, 2000).

\section{Perceptions of primary teaching}

In the earlier Renwick and Vize longitudinal study, the gender of students was recorded, but relatively few analyses by gender were reported as being significant. Nevertheless, the first report in the series noted that the gender balance in 1989 (19 percent male trainees and 81 percent female) was comparable to those of previous years. Wellington College of Education enrolled a somewhat higher proportion of men (25\%); the Auckland College of Education somewhat lower (16\%). Since 1984 , the percentages had only varied one or two percent either way (1990, p. 17). As the figures in Table 1 above show, the gender balance in 1989 was also comparable to those through the subsequent decade.
Based on these results, it would appear that the reduction in the proportion of males in primary teaching positions over the past two decades cannot simply be attributed to a reduction in the proportion being admitted to pre-service primary teacher education. Within the limits of normal annual variation, it has remained relatively constant at around one-fifth of all entrants to pre-service primary teacher education, wherever this may be conducted.

Renwick and Vize note that significant factors which influenced the students' desires to teach were heavily weighted towards being and working with children, and the resultant satisfaction which they anticipated (1990, p. 34). Enrolling students were asked if they had been influenced by others in their decision to take up primary school teaching. Where this was so, they were most likely to be influenced by a particular teacher or parent, but males were particularly likely to have been influenced in their decision by other teachers college students. Male students were less likely than female students to want to teach young children aged 5-7 years, and more likely to want to teach children aged 11 years and older (p. 38). Students in general (including male students) did not foresee any problems in fitting into college life. Finances for daily needs were the major concerns they raised. Intending students, particularly the women, singled out their enjoyment of children and their desire to work with them as being the main reasons for wanting to teach (over $80 \%$ of all students in each case). Over half the students $(56 \%)$ had been influenced by earlier experiences of working with children. This (naturally) was particularly true for mature students.

More than two-thirds of the students expected to make a lifelong career in education, although only half regarded primary teaching as their first choice of career. Just under half regarded primary teaching as a stepping stone for work in other areas in education (1990, p. 36).

Cushman's study of students withdrawing from the Christchurch College of Education led her to backtrack to see if it were possible to find out why so few men applied in the first place. What were the concerns prospective male teachers had when they were considering a career in teaching? A second survey was conducted in 1998 by Year One professional studies lecturers at the Christchurch College of Education with their male students, and 83 out of the total male enrolment of 99 replied. Three areas which had been repeatedly highlighted in the media were used as the basis for focus questions, and the students were 
also given the option of referring to other concerns where appropriate, and of saying whether they knew of other people who had considered a career in teaching but decided not to, for whatever reason.

The first issue was the status of teaching as a career, and 56 percent of those who had gone ahead and begun teacher education expressed some concerns about the perceived status of teachers. About 33 percent were moderately or extremely concerned. Cushman suggested, on the basis of some overseas findings, that men moving into traditionally female professions may see themselves as stepping down in status, when compared to females entering traditionally male fields. "These perceptions may show that men with an interest in, or aptitude for, traditionally female roles are probably discouraged from pursuing them because of negative stereotypes associated with them." Lack of male role models in the school may also indicate that primary school teaching is a more suitable choice for a female than for a male (1988, p. 56).

The second issue was that of salary, and feedback given suggested that about 68 percent saw this as causing some concern, with 41 percent saying that it potentially was of moderate or extreme concern. Until pay parity was instituted in 1998 (actually, just after the Cushman survey was carried out), primary teachers had traditionally been on a lower salary scale than secondary school teachers. Now teachers with identical qualifications and length of experience at primary and secondary schools should expect to receive the same salary. Pay parity has possibly meant that more potential teachers will be attracted to primary teaching, yet as Cushman notes, salaries of beginning teachers are still low compared with those of other professions (1998, p. 56).

The third issue was that of physical contact with children, with all its ramifications in the light of recent child abuse cases highlighted in the media. Some 89 percent of those surveyed listed this as of concern; 67 percent regarded it as moderate or serious. Cushman cites an article in North and South (McLoughlin, 1997) where the author quotes one male teacher as saying "Do you want to know why males are getting out of teaching in such large numbers? It's because all male teachers know they face the risk of a baseless allegation of sexually abusing a pupil. There is a climate of fear that is driving men out of teaching and putting others off becoming teachers" (p. 56).

About half of the men responding indicated that they knew of people who had decided against teaching because of the three issues raised above. While this survey was a retrospective one on a small sample, restricted to a single first-year male cohort in one New Zealand college of education, the results suggest that men considering taking up primary teaching as a career do have misgivings, particularly about physical contact with children, somewhat less about status or salary.

In mid-1998 Cushman also carried out a brief questionnaire survey of a total population of 1006 Year 13 male students from 27 Canterbury secondary schools, in order to assess male attitudes towards these same three issues, which were linked in the literature to the negative image of primary school teaching as a career (Cushman, 2000). A very high response rate was achieved. Some 68 percent of participating students had not considered primary school teaching as a career. Out of the remaining 32 percent, 20 percent had subsequently decided against it. Only three percent had decided to apply for a teacher education course, and the remainder were undecided at the time of the survey (p. 226).

In further analysis of two specific groups - those planning to apply for primary teaching, and those who had decided against applying figures provided show moderate or extreme levels of concern expressed on the part of 33 percent of Year 13 students with regard to the status of teaching, 61 percent with regard to salary, and 53 percent with regard to issues of physical contact. Those who were planning to apply for teaching showed significantly more concern about the status of teaching than those who had decided not to, but there were no significant differences between the groups on the other two issues.

In the discussion of her findings, Cushman noted that a factor deserving of further study was the possible lowering of entry qualifications and training standards, as a mushrooming number and variety of teacher education providers in New Zealand competed for students. High school students planning to apply for teacher education may also have been discouraged from pursuing such a career, and been warned off by other male teachers (p. 228).

Possible lack of awareness by survey respondents of recently negotiated pay parity between primary and secondary teachers was also mentioned as a contributing factor. "On the other hand, pay parity, while giving primary teaching a boost, may not have given it sufficient boost to attain parity with other career options for more able students" (p. 228).

With regard to the third point, physical contact, Cushman notes:

The high media profile given to several sexual abuse cases involving men working with children could take much of the responsibility for the levels of concern toward the issue of physical contact with children. Currently a moral panic in our country has seen an 
unnatural resistance to positive and even nurturing physical contact between adults and children. This fear of allegations of sexual abuse has resulted in schools enforcing "hands off" practices and males being constantly aware of any behaviours which could be misinterpreted. (p. 229)

\section{Subject preferences}

Primary school teachers need to be confident in teaching across the whole curriculum, and competent in each curriculum strand. But when commentators criticise the competencies of beginning teachers they tend not to differentiate between lack of prior knowledge by the beginning teacher and inadequate pre-service education. For instance, following the much-publicised mediocre performance of New Zealand pupils in the Third International Mathematics and Science Study (TIMMS), the Education Review Office (ERO) stated that, "Many teacher education programmes require or provide very little study of these subjects beyond familiarity with the curriculum documents" (Education Review Office, 1999a, p. 30). The report also castigates teacher education providers for not identifying subject knowledge gaps when selecting students, claiming that applicants may not have studied art or music since Year 9, or mathematics and science since Year 10.

The TIMMS report found no direct relationship between the general qualifications of New Zealand teachers at the mid-primary level and their students' achievement in mathematics and science. This report did not ask about specific subject areas, but notes that the extent of mathematics and science knowledge of trainee teachers at the primary level "remains an area of concern" (Garden, 1997, p. 180). Here the authors cite a report of a small-scale study of 92 trainees in Wellington Teachers College (later to be renamed the Wellington College of Education), made some time previously (Clark \& Vere-Jones, 1987). In stating that "teachers' lack of knowledge in mathematics and science contributed to the relatively poor performance of New Zealand pupils in the study," the Education Review Office would appear to have gone beyond the intent of either of these surveys, which make no attempt to attribute causality. The relationship between teachers' qualifications in mathematics and science and the performance of their pupils at the primary school level in New Zealand would not yet appear to be clearly established. Neither report mentions teacher gender in this respect.

However, by the time student teachers begin training, there is no doubt that their subject strengths and preferences are already established, and the associated "culture" is frequently already gendered. There is evidence that girls feel more "alienated" from some subjects, notably mathematics and science. As Corkery states:

In secondary schools, the curriculum is separated into subjects and boundaries between each discipline are evident. Students often choose subjects they feel "at home" in. They may choose subjects according to who they think will teach them, so feelings about teachers can be transferred onto the subjects. Thus the subjects acquire a culture or character...." (2001, p. 11)

Following up their 1989 en try cohort, Renwickand Vize found evidence that male students preparing to teach at the primary school level were more likely than females to be looking forward to teaching science and physical education. They were least likely to be looking forward to teaching music. Female students were more likely than males to be looking forward to teaching reading (1990, p. 65). Mathematics was the subject where the highest proportion of students felt they needed special help $(23 \%)$, and it was the subject that students were least looking forward to teaching (p. 66). But it was also the subject in which students felt their confidence had most increased by their second year on the course (1991, p. 6).

In their third year at college (the final year for most) computing was added to the list of subjects male students were most keen to teach. They were also more likely to express confidence in using computers to assist children's learning in the classroom (1992, pp. 37-38, 48). At this stage students were also more likely to have a preferred age group they would like to teach, with a greater proportion now stating a preference for older children, but no gender difference was reported in this regard (p. 74).

\section{Cultural adjustment}

Students at colleges of education need to adapt to a particular institutional culture in which there is increasingly an imbalance of male and female staff.

Renwick and Vize reported the situation in 1989, in the three colleges of education they surveyed, when women were in a clear majority amongst students, but men predominated amongst the staff. They noted that staff changes in 1990 had improved the balance (1991, p. 122). But by 1999, one-third of the lecturers at New Zealand colleges of education were male, two-thirds female. The balance had clearly 
swung over the decade. This pattern tends to replicate the pattern in a typical primary school, where the gender imbalance is likely to be even greater. Many smaller primary schools now may have no male teachers at all.

As Corkery notes:

Colleges of Education try to model as well as teach "best practice". This being the case, classroom teaching will accommodate the specific learning needs of individual learners in the classroom in the same way that lecturers expect teacher trainees to do.

Teacher education is only occasionally delivered in the form of "direct teaching" or mass lectures. Usually the two hour sessions resemble interactive student-centred workshops similar to the pedagogy of a primary classroom. As most teacher educators are female primary teachers this is not surprising. It is assumed that the principles and techniques used in the education of children are equally effective in educating adults (2001, p. 21)

And, as has already been noted in the section above on withdrawal, courses designed with secondary school leavers in mind, and staffed largely by former primary school teachers used to teaching young children, may not provide an environment in which adults feel comfortable. Many of them are returning to teach after raising families, or after having followed other careers less demanding of intensive study, and their needs may not be well served by current college programmes and pedagogy (Cushman, 1998, p. 54). College timetable structures and teaching styles also show strong similarities with schools, and students are required to spend long days in college classrooms, rather like school settings. But it is not clear whether male students find this institutional and instructional culture less appealing than female students. The jury is still out.

\section{Curriculum issues}

There is a large international literature focusing on different cognitive styles, and many have attempted to make generalisations on the basis of gender. While most of the gender-based research deals with students in schools, some findings are translatable to tertiary contexts (Corkery, 2001, p. 22). This is a highly contested field, and Alton-Lee and Praat (2000, p. 40) outline no fewer than seven possible theories of gender difference, beginning with psychoanalytic theory, continuing through six other theories drawing their support from the fields of human development, psychology and sociology. Close to one extreme is the Essentialist, in which male and female are regarded as biologically different; these differences lead to essential differences in their behaviours. At the other extreme are Social Constructionist theories, postulating that children construct their own knowledge through their complex interactions with a gendered environment, and more recent Post-Structural theories, not yet widely accessible to educationists, which are concerned with "breaking down the male/female binary that is seen to influence how we think about the world, and to constrain the possibilities for males and females" (2000, p. 43)

Corkery notes that:

There is little research which focuses on gender disparities in learning in tertiary education. However, if we take the essentialist view, we may be concerned that a learning environment dominated by one gender may present problems for students of the other gender. (p. 23)

She cites a 1995 Unesco Institute of Education International Colloquium on the topic "Is there a pedagogy for girls?" and notes the suggested elements of a "multi dimensional gender-sensitive pedagogical strategy" for co-education (both boys and girls) as including the following:

- Using more co-operative and interactive modes of learning

- Linking mathematical and scientific content to societal issues

- Emphasising discussion and collaboration as well as competition

- Allowing class discussion and quiet reflection

- "Private" as well as public questioning and probing of the pupil by the teacher

- Slowing the pace of a lesson and encouraging pupils to use the time to compose responses

- Giving feedback that balances criticism with precise guidance and praise, not the bland praise for "dutiful hard work" which girls currently tend to receive

- Balancing the presentation of male and female historical figures, scientists, etc., in teaching materials and computer software

- Using assessment that supports learning and reflection, rather than relying just on competition with others.

(Corkery, p. 24, citing Murphy \& Gipps, 1996, p. 75)

On the other hand, if more recent theories of learning are embraced, the issue becomes not one of catering for presumed differences between 
boys and girls, but of improving teachers' understandings of "gendered processes", and of downplaying the emphasis on supposed differences in learning styles and cognition between the genders, in an attempt to find teaching strategies which enhance learning for all students. The intent is not to discover appropriate pedagogies for boys and for girls, but to accept individual diversity as desirable, and view it as a function of a whole range of influences, both personal and social, of which gender is only one. But to go beyond this and suggest that the current pedagogy is a barrier to recruitment and retention of men in primary teaching would be to take a position not yet substantiated in New Zealand.

It has often been argued that many women preparing to be primary teachers are not "comfortable" with mathematics and science, and that some men are less than enthusiastic in literary pursuits. But how to change the culture of the country's teacher education institutions to compensate for this presumed imbalance is less than clear. Making mathematics and science more language-based has been suggested, and it is reported that mathematics in colleges of education has moved to a more co-operative problem-solving endeavour, and that science is becoming more interactive and holistic. Other writers have suggested such things as the use of journaling in mathematics, and writing in science, or cross-curricular strategies such as mathematics-language initiatives as a possible way forward.

Whether these changes would attract into primary teaching more young men who were high-achievers in mathematics and science in the upper secondary school is a moot point. Detractors would argue that a more "girl-friendly" curriculum is not the answer, and may disadvantage other ethnic groups as well as boys.

\section{Men Moving into Teaching Positions}

\section{Demographic trends}

Numbers of primary teachers graduating from some form of state preservice teacher education course over the last decade show an increase, but the proportion of males has remained fairly static at between 18 and 20 percent (Table 2). These figures are not too dissimilar from the proportions of total enrolments, although somewhat less than the figures shown in Table 1, in each of the corresponding years. However, they cannot by themselves explain the decrease in the number of men teaching over the period.
Table 2 Pre-service primary teacher education graduates, by gender

\begin{tabular}{lrrrr}
\hline & $* 1994$ & 1995 & 1998 & 2001 \\
\hline Male & 260 & 265 & 353 & 539 \\
Female & 1,053 & 1,069 & 1,569 & 2,306 \\
Total & 1,313 & 1,334 & 1,922 & 2,845 \\
$\%$ male & $19.8 \%$ & $19.9 \%$ & $18.4 \%$ & $18.9 \%$ \\
\hline
\end{tabular}

Source: Ministry of Education Database 1994, 1995, 1998, 2001

* Breakdown by gender not available prior to 1994

\section{Leaving pre-service education}

When men graduate from teacher education there are generally teaching opportunities for them in New Zealand, provided they are mobile, that is, prepared to move to a centre with a vacancy, although the particular demographics of numbers of primary-aged children in any particular year will have a bearing on this. Because of the population distribution, many more of the teacher vacancies tend to be in the north of the North Island, particularly in greater Auckland, and a move to this area for people from the south may be inconvenient and expensive, particularly for those with dependants. Recent figures suggest that it is becoming more difficult for both men and women to move into Year 1 positions immediately upon graduation from current three-year teacher education programmes.

There is some (largely anecdotal) evidence that New Zealand men may be the first to gain employment, after graduation. Yet some men choose not to go teaching, and it is important to ascertain why this may be so. The New Zealand research evidence is sparse, and it is hard to gain accurate knowledge of graduates' placements after leaving preservice teacher education. Some United States research has found that many who did not go teaching after graduating had no intention of remaining in the teaching service, and that attrition was higher amongst those with attractive non-teaching alternatives (Darling-Hammond \& Sclan, 1996, pp. 72-73). This seems a plausible finding, and may also be true in New Zealand.

Renwick and Vize reported that in their longitudinal study in the early 1990s they found no significant differences by gender in terms of 
likelihood to get jobs, although those aged between 20 and 29 had by far the greatest chance of being offered a job. This was the first year in which graduates from colleges of education were not placed in schools by the Department of Education, and so generally had to compete for positions in a competitive market with more experienced teachers. At least a quarter were still looking for full-time teaching jobs one year after graduation, although they believed they were as well qualified as those who had gained jobs, and were finding employment in a teacherrelated activity (p. 6)

In another study, a sample of 224 beginning teachers (13\% male) who had trained at the Auckland College of Education, plus 127 principals who had advertised first-year positions in the Auckland area, were surveyed about their views on the selection process for beginning teachers. In this survey, conducted in late 1989, it transpired that males were a little more likely than females to receive offers of teaching positions, but once again, younger teachers, both male and female, were more keenly sought by principals. Prior qualifications and length of teacher education courses undertaken (three-year, or two-year graduate), appeared to be unrelated to the number of job offers received (Cameron et al., 1990, p. 2).

As far as the principals were concerned, personal factors such as age, gender, ethnicity, and family circumstances were not regarded as important in influencing their final selection of beginning teachers. What was important to them was an expressed commitment to teaching, a good fit to the job description, including subject strengths offered, an ability in spoken English, and personality factors which would enable the beginning teacher to "fit in" with the existing staff and the local community. In this respect, one principal may have expressed the unspoken views of others when he was so bold as to say "I'm looking for a male as the staff are all female."

Two years later, a further study was carried out by the same authors, surveying a group of 95 principals who had advertised beginning teacher or basic Scale A positions in late 1991. Unlike the first, this study did not survey student perceptions. Principals rated commitment to teaching, quality of spoken English, overall appearance and personality very highly in factors they were looking for in beginning teachers. They claimed that they chose the person best suited to the job, but considered factors such as gender, ethnicity and age when there were two candidates of equal worth. The following quote is revealing:
The over-riding principle is the best person for the job; however, there are equity considerations for cultural background and gender, yes ... in [a] staff of 20 there is just 1 male in a classroom, so gender equity would have to be more men. (Cameron \& Grudnoff, 1992, p. 3)

This was borne out by the evidence that more men, proportionally, were successful in gaining positions. Men also tended to be appointed more often than women to full-time permanent, rather than relieving, positions (p. 3)

\section{Preparedness for teaching}

There was almost unanimous agreement amongst graduating students in the Renwick and Vize survey that they felt "confident" or "very confident" about teaching and running an integrated curriculum programme in their own classroom. Over 90 percent also felt very confident about their knowledge of curriculum content in language, mathematics, physical education, and art. However, they were not at all confident about the curriculum in music or Maori (1992, p. 4). No gender differences were reported in these respects.

Once in the classroom, by the time they had reached the third term (two-thirds of the way through the school year) in their first year as beginning teachers, most of the students interviewed were reported as having now "come through the 'wobbly stage', and with help and guidance from more experienced teachers, and constant practice, were generally riding along quite confidently" (1993a, p. 3).

In a follow-up of their study on beginning teachers in the Auckland area, Cameron and Grudnoff asked principals who had employed graduates from the Auckland College of Education to comment on specific strengths and weaknesses shown by their beginning teachers which they considered could be attributed to their courses at college. Some 255 beginning teachers were rated, and the principals reported that they appreciated the personal characteristics of their beginning teachers most. No gender differences were reported.

By and large, principals are very satisfied with their (own) choices of beginning teachers. They found personal qualities better developed than professional skills, which is not surprising; beginning teachers have had at least twenty years learning to be people, and only a short period learning to be teachers. (Cameron \& Grudnoff, 1993, p. 3) 


\section{Men in the Classroom}

\section{Common concerns}

In November, 1998, a sample of 253 randomly selected male primary teachers in Canterbury schools was surveyed to determine levels of concern on three major issues: status, salary, and physical contact with children (Cushman, 1999). These were the same three issues alluded to above, upon which the author canvassed the views of male college of education students who had withdrawn in their first year of teacher education, and male Year 13 secondary school students considering teaching as a career (Cushman, 1998, 2000). The sample was selected by approaching 150 primary and intermediate school principals, all of whom agreed to participate by circulating the questionnaire forms to eligible teachers, namely, those on their staff with more than two years teaching experience. Twenty-eight schools (19\%) out of the 150 had no male teachers, but from the remainder there was a 93 percent response rate of teachers surveyed. The results should have good validity as a representation of the situation in Canterbury, although it would be unwise to extrapolate to all New Zealand primary and intermediate schools.

The study provides further evidence that the three issues raised are major concerns for practising male teachers, just as they were for male Year 13 students considering going teaching and male pre-service teachers in their first year of teacher education. Furthermore, the level of concern increased with age and experience.

\section{Status:}

Whereas 52 percent of all respondents rated status to be of moderate or extreme concern, 76 percent of those aged over 50 judged it this way; principals were particularly likely to express major concern on this issue. Young teachers under the age of 30 were not unduly troubled. Cushman reported that many older male teachers still felt that teaching was an undervalued profession, and cited Garden's findings that those teaching Standards 2 and 3 (Levels 4 and 5) rated their own social status very lowly, closer to labourer than to other professionals such as doctors, lawyers, or accountants. Garden found that as many as twothirds of these teachers believed that "society did not appreciate their work", but, interestingly, recorded their belief that their own pupils did not share this negative view (1997, pp. 190-191).

Principals were particularly concerned about some parents' attitudes, and reported teachers being dominated and belittled, being held accountable for supposedly poor literacy results and maladjusted children, but on the other hand not granted the respect they deserved for their dedication, and being expected to compensate for the social breakdown of at-risk families and broken homes.

Other concerns related to status expressed by male teachers in this Canterbury survey were the perceived lack of a career structure, which allowed potentially very good male teachers to be enticed out to greener professional pastures providing more opportunities, plus a general lack of understanding of the complexities involved in being a competent teacher in today's society. They also regarded the training of male teachers as a contributing factor in declining teacher status, with a reduction in the length of some teacher education courses introduced in 1998, a lowering of entrance standards, and consequent reduction in the quality of beginning teachers (Cushman, 1999, p. 79).

She concluded:

There would appear to be a general consensus among male teachers that the status of the teaching profession has been eroded. The complex range of issues which have contributed to the erosion range from the selection of teacher trainees and lack of career structure to the unrealistic expectations of parents and politicians, including the unwarranted media attention given to ERO reports and union spokespeople. (p. 80)

Salary:

Some 48 percent of all respondents rated salary to be of moderate or extreme concern, but following the significant salary rise which gave them parity with secondary school teachers in mid-1998, younger male teachers in particular did not regard it as an issue. Concern rose somewhat with age and experience, with senior teachers, assistant and deputy principals expressing most concern. Principals, in general, were reasonably satisfied with their salaries.

Cushman noted that while there was some general dissatisfaction with teacher salaries, many respondents pointed out that they were not teaching for the money. Nevertheless, many still felt that teaching was an undervalued profession, in which the salaries did not really reflect the hours worked, the commitment required and the level of responsibility and management skills demanded.

Status and salary are inextricably linked, and while suggestions that teachers do not teach for money, and that higher salaries might not attract the right kind of person are valid ... more competitive salaries 
would enhance status and perhaps attract a greater number and range of applicants. (p. 81)

Physical contact with children:

Seventy-two percent of male teachers rated physical contact with children (and possible ramifications) as of either moderate or extreme concern, and in a profession where, by its very nature, such contact is likely to occur on a daily basis, the implications for classroom practice are clear and disturbing. Young teachers were much less concerned than older ones in this respect, but the terms "vulnerability" and "fear" were often mentioned by older teachers (p. 83).

The fact that young teachers were less concerned about physical contact than older teachers may reflect lack of experience, or perhaps the idealism of youth. Cushman also notes that the higher the level of responsibility, the higher the level of concern. This was particularly true of principals. "Because any allegation of teacher maltreatment of children inevitably comes to the notice of the principal, it is understandable that they are likely to be sensitive to issues which have enormous implications for the reputation of their school" (p. 83).

Male teachers working in junior classrooms were particularly likely to express concern. Young children demand and expect physical contact with adults with whom they have a relationship, and it is not surprising that men teaching children in this age group are particularly sensitive to this dilemma. For some, it has meant a refusal to teach juniors. Many expressed regret that they felt unable to comfort a distressed child in the same way as a parent or female teacher could, without putting themselves at risk.

Cushman reported that men teaching older pupils were also concerned that they may be vulnerable to being "set-up" by street-wise girls and placed in embarrassing situations, and this vulnerability meant that they found difficulty in treating the genders equally. Children could also be denied seeing a male teacher's compassionate side. Male teachers working in one-on-one situations such as reading recovery felt particularly at risk (p. 84).

She concluded:

The issue of physical contact with children raised the highest levels of concern for practising male teachers. The current climate of "moral panic" which has pervaded society following close media scrutiny of several sexual abuse cases has led to protective safety practices in schools which are confining, stressful and confusing for both children and male teachers. That many schools have chosen to react in this way is, in part, understandable, but it has only served to reinforce unhealthy beliefs and encourage stereotypical male role modelling behaviour. (p. 84)

\section{Role acceptance}

Respondents in Cushman's survey were also asked to rate their concerns about working in an occupation where most employees were female. The answers tended to fall into two categories, depending on whether the effects were regarded as relating to the children under the male teacher's care, or to the teachers themselves.

She reported that by far the greatest perceived need was for more role models for children, particularly those growing up in sole parent families without any male parent present. However, not all chose to elaborate on their statements as to what sort of role model was needed. Recurring themes were the need to be exposed to a wider variety of role models than children, particularly boys, saw on TV (often highlighting violence); the need for men to be present to empathise with boys and relate to them as only males can; the need to see sensitive and caring behaviour modelled by men (with the corollary that there should be more males in junior classrooms); and the simple need for greater "balance" on school staffs, bringing a greater richness to the school environment. This also implied the need for a better gender balance in management positions, where men have long predominated. There were also some suggestions that the predominance of women in the classroom carried with it a danger of a "feminisation" in curriculum delivery, which did not serve students as well as a more balanced learning environment would.

Aside from these issues related to children, the reaction of males to working in a largely female environment was mostly positive. Being relied upon to "pick up stereotypical male roles such as disciplining, fixing photocopiers and computers, and organising sports gear" was only mentioned by one young teacher (p. 86).

Cushman reported a few men wanting more male company, giving opportunities for "male chat", and a few instances where being part of a minority group caused tension or intolerance. Some experienced teachers who had been in schools where there was a more equal gender balance found there was a different (and presumably preferable) atmosphere, but others stated that it was "the individual that is important, not the gender." 
She summed up as follows:

Although research suggests that the notion of male role-modelling is overworked and under-substantiated, those working at the chalkface strongly believe that positive male identities are important in schools as role models for all children, particularly those without significant positive male relationships outside the school. Theimportance of male teachers for purposes of academic achievement and behavioural control was not evident in the male teachers' responses in this survey, nor was the suggestion that the supposed "feminisation" of teaching is responsible for the rebellious behaviour of some boys. Rather, the need for schools to be more closely aligned to, and representative of, the communities in which children must function was a recurring theme. (p. 87)

\section{Retention}

Some men graduate from teacher education courses but do not go teaching. Others teach for a few years and then resign. The question needs to be asked whether the proportions who either choose not to go teaching at all, or who embark on another career path in short order are different for men and for women.

Table 3 shows the numbers of primary school teachers in New Zealand schools, viewed over a similar period in the past decade as that presented in Tables 1 and 2. The trend for declining proportions of males is clearly apparent. Whereas the percentages of males enrolling in pre-service education and graduating from pre-service education have remained roughly constant, fluctuating around 20 percent, these figures, based on the much larger total numbers in the primary teaching workforce, are all moving in one direction - down.

Table 3 Primary teachers in New Zealand schools, by gender

\begin{tabular}{lrrrr}
\hline & 1992 & 1995 & 1998 & \multicolumn{1}{c}{2001} \\
\hline Male & 4,925 & 4,576 & 4,545 & 4,433 \\
Female & 17,364 & 17,474 & 19,141 & 19,686 \\
Total & 22,289 & 22,050 & 23,686 & 24,119 \\
$\%$ male & $22.1 \%$ & $20.8 \%$ & $19.2 \%$ & $18.4 \%$ \\
\hline
\end{tabular}

Sources: New Zealand Education Statistics 1992, 1995; New Zealand Teacher Census 1998, 2001
From 22 percent in 1992 the figure has steadily dropped to 18 percent in 2001, and the actual numbers of men in primary teaching positions have also declined to correspond over the decade. The numbers of women teaching in primary schools have shown a steady increase (with a sudden jump in 1998). In sum, over the decade, the number of women in primary teaching has increased by 13 percent; the number of men has decreased by 9 percent. This is a trend which is not peculiar to New Zealand; it has been detected in a number of other countries over the past decade

\section{Work Pressures}

This next section considers some New Zealand findings relative to issues and pressures in primary schools over the last decade, drawn in part from the author's own research (Livingstone, 1994, 1999). The 1994 study was based on a sample of 160 primary and intermediate teachers drawn from a random sample of 29 state and state-integrated schools in the greater Wellington region, weighted to favour small schools, and including their teaching principals. The 1999 survey was based on a random national sample of 192 teaching principals in state and stateintegrated schools.

Some common findings emerged from the two surveys. Teaching workloads had risen substantially in the five years prior to the surveys, and this had impacted heavily on the family and general social life of these classroom teachers and teaching principals. A considerable amount of school-related work was being done in the weekends, and in holidays, reflecting the reality that more than half these teachers' work was done outside face-to-face teaching hours. Much of this workload pressure related to the demands upon primary teachers brought about by the rapid implementation of a large number of new curricula, and associated administrative paperwork in the new teaching environment introduced by the Tomorrow's Schools reforms. The median working week for the 1994 Wellington teacher sample was estimated at 54 hours, plus another 6 hours in the weekends (1994, pp. 12-14). The teaching principals surveyed five years later worked even longer hours, with a median of 61 hours, plus over 6 hours in the weekends (1999, pp. 30-32). A re-analysis by gender showed there were no differences between males and females in their median working weeks.

A further re-analysis showed there were very few significant differences between men and women, in either survey, when they were asked to rate a series of more than 40 different statements which might 
have represented causes of workload pressure or stress for them. In the 1994 teacher survey, men were significantly more likely to rate their involvement in fundraising, and promotion/career opportunities (or the lack of them) as factors causing them stress. In the 1999 survey of teaching principals there was only one marginally significant difference, in that men found the introduction and implementation of new curricula somewhat more stressful than women did.

For both men and women, the six main stress factors were exactly the same in 1999 as they were in 1994. The amount and nature of the extra paperwork required came easily top of the list in both; and then followed the simultaneous implementation of many new curricula, the pressure caused by ERO school reviews, the number of hours they had to spend at work, the development of new assessment procedures, and the ways in which change was being implemented (1994, p. 31; 1999, p. 64).

In both surveys, teachers were asked, if they were able to make a choice, whether or not they would stay in teaching. Of the 1994 sample, 38 percent said they would leave if they could (1994, p. 35). The corresponding figure in the later survey was 40 percent $(1999, \mathrm{p} .71)$. A re-analysis of these data by gender showed that the males in both samples were significantly more likely to opt to leave, if they could.

By way of comparison, another recent study of job satisfaction and stress, based on a sample of 353 full-time teachers in the Auckland region (over-sampling schools in low-SES areas), found that there were no significant differences in the general levels of occupational stress reported by men and women, nor between beginning and experienced teachers (Hawe et al., 2000, p. 202). Following a series of factor analyses, the order of the loadings on a series of stress subscales (from highest to lowest) was: Disruptive students, respect for teachers, task overload, financial rewards, quality of resources, and administrative support. There was no significant effect for gender on any of these subscales. But women teachers did report significantly higher levels of job satisfaction than their male counterparts.

However, this finding was not consistent with that from another study of teachers in intermediate schools (Manthei et al., 1996). The authors hypothesise that the relatively lower levels of job satisfaction reported by the men in their study lay in part with their location in a gendered occupation. It may also have related to the year level at the school in which they were currently teaching. The issue awaits further exploration.

\section{The Need for Men Teachers}

The preceding literature review, largely drawn from indigenous sources, goes some way towards providing a rationale for having more male teachers in primary schools. But there are relatively few robust New Zealand research studies which address the issue, even obliquely, and findings from overseas (particularly the large volume of research from the United States) may not necessarily apply in this country.

Four main reasons have been advanced in recent years, arguing for more men in primary education. They can be summarised as follows:

- Academic: To address perceived learning deficits of boys

- Social: To cater better for perceived social needs of boys

- Environmental: To reduce an overly "feminised" nurturing ethos in primary schools

- Representational: To make primary school staff more representative of society at large.

There is no doubt that there is widespread national and international concern about the proportions of male teachers in schools. Alton-Lee and Praat argue that these concerns "are justified within a perspective where diversity, representation and positive interactions between children of both genders are valued in the way a society socialises its young" $(2000$, p. 59). There is much less consensus about the presumed effects of the phenomenon and the validity of the claims made above.

Farquhar (1998), in her review article drawing largely on conference papers, journal and newspaper articles, and focussing on early childhood education, argues that the value of having teachers of both genders is largely social and psychological, but that this in turn has educational benefits. If the teaching profession is representative of the whole community, then the message conveyed is that education is also for everyone. Children will then have the opportunity to interact with, and learn from (and with), a diverse group of adults.

She cites a variety of sources arguing the following benefits for having a better balance of male and female teachers in primary schools: (pp. 175-176)

- Boys are more likely to admire and copy the behaviour of their male, rather than their female, teachers.

- Boys' interests are more likely to be respected and catered for by male teachers (e.g., more boisterous play). 
- Boys can observe that it is acceptable for men to participate in the care of children.

- Male teachers are important for boys and girls who do not have a father at home, or who are brought up mainly by their mother.

- Male teachers can provide a stable, positive male figure for children whose "fathers" are constantly changing, or regularly absent from home.

- Exposure to positive male role models during the early years may help to counter social problems such as youth suicide, bullying, and truancy, which affect boys more than girls.

- Male teachers are the only ones able to develop and model ideas of masculinity.

These are all entirely plausible, but robust research studies are necessary to validate them thoroughly for New Zealand.

In more specifically early childhood settings (which would also apply to junior school classes), Farquhar notes some further advantages in having more men on the staff:

- signalling to fathers that they are welcome in the school, and have a valuable part to play in their children's education;

- sensitising female teachers to the possibility of their own (possibly latent) sexist attitudes, through having more contact with male teachers on the staff.

\section{Academic}

As far as academic achievement of boys is concerned, in their comprehensive examination of the international research literature, Alton-Lee and Praat note the existence of a longstanding gender gap in favour of girls in reading, literacy and English in primary schools, in many countries $(2000$, p. 295). It appears girls read sooner and more fluently than boys, and say they enjoy it more. Although international comparisons over time have shown New Zealand primary school students generally perform very well in literacy tasks, girls still do better than boys. Years 4 and 5 girls also did a little better than boys in both mathematics and science in the Third International Mathematics and Science Study, conducted by the IEA, although the differences did not reach normally accepted levels of statistical significance (Garden, 1997, pp. 68-69, 113).
But the picture is quite a complex one. The relative achievement of boys and girls differs by curriculum area and school level, and the range of variability within gender groups is much greater than the variability between gender groups. Gender differences in primary school achievement from the most recent rounds of the ongoing assessments conducted under the National Education Monitoring Project (NEMP) help to demonstrate this. They could be summarised briefly as follows:

- Differences between boys and girls at Year 4 and Year 8 in aspects of technology were negligible (Crooks \& Flockton, 2000a, p. 48).

- Girls outperformed boys in music consistently at both levels (2000b, p. 49).

- Girls did substantially better than boys in reading and speaking at Year 4, a little better in Year 8 (2000c, p. 66).

- Girls performed better than boys in information skills at Year 8, but not at Year 4 (2001a, pp. 48-49).

- Boys did substantially better than girls in Year 4 mathematics, slightly better in Year 8 (2001b, p. 64).

- The differences between boys and girls in Year 4 and Year 8 social studies were negligible (2001c, p. 62).

Some overseas research has suggested that a "girl-friendly" environment in a classroom perpetuated by women teachers may be responsible for the better performance of girls in subjects associated with literacy. Some claim that reading and writing is regarded as feminine and passive, not fitting in well with the active, more practical focus of the masculine identikit. More male teachers displaying a passion for reading might help to overcome this.

In the absence of any substantive research linking teacher gender with such results, and realising that in the majority of New Zealand primary schools this wide array of subjects will be taught by the same teachers, it is difficult to draw strong conclusions from these results about the likely impact on the achievement of boys in various subjects of the curriculum if there were more male primary school teachers. From their perspective, Alton-Lee and Praat argue:

Our review suggests that teacher specialist subject knowledge should ideally encompass both subjects traditionally positioned as feminine, and subjects traditionally positioned as masculine. The teachers understandings of cultural and gendered difference and processes are instrumental in the way curriculum is enacted. (p. 310) 
In cautioning against placing too much importance on disparities in academic achievement based on gender, they consider that the quality of the classroom teacher is a more significant factor than the gender of the teacher in successfully implementing a very diverse primary curriculum.

\section{Social}

Nationally and internationally an increasing number of children are being brought up in families where there is no father figure. Boyer and Baptiste, in their review of the recruitment and retention of minority group teachers in the USA, note that:

If 16 million children do not live with their fathers, the presence of adult males in classrooms may be one of the most empowering policies that could be initiated. The crisis involves the recognition of the significance of modelling within the classroom. The absence of males in elementary classrooms is equivalent to the devaluing of the educational experience for all males. (1996, pp. 786-787)

In New Zealand, it is estimated that some 60,000 boys are growing up in households without a father present. Nearly all single-parent families are headed by women. Even when a father is present, the demands of his job may encroach on evenings and weekends, and he may be prepossessed by work and remote from his children. The term "underfathered" has been coined by Australian Steve Biddulph to describe such families, in which the absence of a man to embody masculinity may hinder healthy gender identification in boys (Biddulph, 1997). If the view is taken that gender is constructed by interactions within family, schools, peer groups and the media, then boys need male role models so that they can learn what it is to be male. If these interactions are restricted, boys are more likely to struggle with gender identification.

Increasing the number of male teachers in primary schools is seen by some educators as a positive step in countering such behaviour as bullying, truancy and youth suicide, all more frequent amongst boys than girls. New Zealand boys figure more largely than girls in suspension and expulsion statistics, and the country has high rates of alcohol abuse, drug dependency, and crime amongst adolescent boys. The argument is not that male teachers per se can actually prevent these problems, or even nip them in the bud, but that they can serve as effective role models who can demonstrate to boys more positive ways of coping with pressure and conflict. Such researchers claim that it is important to see male and female teachers working cooperatively together in this regard, sharing in the care and responsibility for children, and providing positive role modelling for children who often segregate themselves into "boys only" and "girls only" play areas and activities at this age.

There is also a stream of thinking which suggests that boys and men may have more stereotypical views of sex roles than girls and women. If this is true, they may be less likely to enter areas of endeavour which they regard as "women's work". By so doing they limit their occupational choices, in ruling out large areas within the medical profession, for example. The presence of more men in schools might help to remedy this perception, through challenging such stereotypical attitudes.

\section{Environmental}

Some researchers suggest that a "girl-friendly" environment in the classroom promotes superior verbal skills amongst girls, and that boys react against this by exemplifying a concept of masculinity which regards books and reading as "un-cool" feminine behaviours. Others have suggested that practices in literacy, such as self-disclosure and creative expression, sit more comfortably with girls than with boys. Negative attitudes of boys' (and girls') fathers may reinforce such perceptions.

Early childhood researchers, in their studies of the different ways in which men and women interact with young children, have noted different preferences for "play" among male and female teachers. Women in general are more interested in craft and dramatic activities, rather than construction, climbing and ball games. Men have a preference for physically oriented equipment and activities, and are likely to cater better for boys' more boisterous interests and needs.

The question of whether women have a different way of implementing the curriculum than men, a way which may be more suitable for girls than boys, has been addressed in the literature. But the evidence appears slight that men, in general, have a teaching style more suitable for boys, and women, in general, share a teaching style more appropriate for girls. However, the ideas of the "feminisation" of the curriculum and the nature of a gendered pedagogy in the primary classroom are still open topics for research. 
Other assertions have also been made in Britain and the United States about what has been termed a "discourse of denigration", in which the teaching profession has been blamed for boys' failure. Delamont (cited in Alton-Lee \& Praat, 2000, p. 268) critically examined the research on five problems commonly blamed on the "feminisation of teaching": a lack of a scholarly role model for boys; a bias in favour of feminism in the curriculum; a lack of toughness in discipline; a rejection of competition in academic and sporting matters; and a classroom regime favouring females. She questioned many of the underlying assumptions, such as those stereotyping women teachers as nurturing, anti-competitive, sports-phobic people, while males are stereotyped as tough, competitive, sports-loving, and better at motivating the "macho" lad. The sparse research evidence was not compelling.

The difficulties of adequately mentoring male students and male teachers in predominantly female-staffed teacher preparation institutions and schools raises another issue. If males are in such small minorities, they may lack the encouragement and support of others of their own gender when the going gets tough. This observation rides on the back of a plea for more "authentic research" in studying culturally different teachers in the United States, and applies to males in primary teaching as much as it does to ethnic minorities (Boyer \& Baptiste, 1986, p. 783)

It is hard to escape the argument that a balance of both men and women in primary school classroom environments is the ideal. This observation naturally leads on to the final proposition.

\section{Representational}

This is essentially an argument in favour of diversity. Society is a diverse place, and primary schools should be microcosms of society. As far as teaching styles are concerned, there is a wide range in New Zealand schools. A better gender balance in the primary teaching force would increase that diversity, and one would hope, the tailoring of those teaching styles to the needs of all children, both boys and girls. There is no need to create an artificial polarisation between the approaches of men and women teachers.

If there are indeed differences between men and women in the gendered culture associated with the various school subjects, then a better gender balance of teachers in primary schools, early in the learning experiences of children, would be to the advantage of all children, both boys and girls, widening their curricular horizons and engendering diverse enthusiasms.

There is a strong argument in favour of providing a broader range of role models, more representative of society at large, early in the educational process. Men who show warm and sensitive fathering and nurturing qualities need to be seen alongside those who demonstrate more physical, boisterous and competitive traits. By no means all men display or value "macho" attributes, and young children should have the opportunities to appreciate this.

A variety of male and female teachers in primary school classrooms, while reflecting more accurately the makeup of society, also telegraphs to children that teaching is a plausible career for both men and women. It should help to break down the common stereotype that any occupation which involves work with children should predominantly be carried out by females.

\section{Conclusion}

Corkery summarises the arguments well, in expanding on the logic in the four basic premises which began this section. The following four propositions draw heavily on her work:

- Seeing more men involved in primary education should enhance boys' motivation to achieve academically.

- More men in primary school environments will provide more reference points or models (though not necessarily exemplary ones) for boys, and broaden their behavioural and attitudinal options.

- More men in primary schools will counter a prevailing feminisation of the learning environment for children and extend the range of curricular enthusiasms in primary classrooms. This will subsequently make the atmosphere in schools comfortable for a wider range of men and boys.

- Adults involved in primary education should be more representative of the communities they serve, so that the message goes out to children that learning and academic achievement are for everyone. (2001, p. 61).

While all four propositions above have some validity, perhaps the final one carries most weight, and is thus able to provide the most unequivocal support for the compelling argument in favour of having more men in primary school classrooms, and not just in the principal's office. 
Note

1. This review is an abbreviated version of a small book by the author to be published in September, 2003, and focuses on major reports and research studies carried out in New Zealand settings, mainly over the past ten years. It does not purport to deal with the wide international literature on the subject of men in primary school teaching. Such works can be traced in the substantial references given in many of the works cited in the bibliography,e.g., Alton-Lee and Praat, Corkery, Cushman, Farquhar and Trembath. There are also a large number of more ephemeral and anecdotal articles in New Zealand newspapers and journals which, in general, are not referenced, although they have influenced the tenor of the concluding discussion. They, too, can be traced in the bibliographies of the references cited. It must be accepted that the number of substantive New Zealand research studies on the topic is not large, and this review may suffer from over-reliance on the few studies which have been carried out.

\section{References}

Alcorn, N. (1999). Reviews of teacher education in New Zealand 19501988: Continuity, contexts and change. Waikato Journal of Education, $5,63-76$.

Alton-Lee, A., \& Praat, A. (2000). Explaining and addressing gender differences in the New Zealand compulsory school sector. Wellington: Ministry of Education.

Biddulph, S. (1997). Raising boys. Sydney: Finch Publishing.

Boyer, J., \& Baptiste, P. (1996). The crisis in teacher education in America: Issues of recruitment and retention of different (minority) teachers. In J. Sikula (Ed.), Handbook for Research on Teacher Education (pp. 779-794). A project of the Association of Teacher Educators. New York: Macmillan.

Bricheno, P., \& Thornton, M. (2002). Staff gender balance in primary schools. Research in Education, 68, 57-63.

Brookhart, S. M., \& Loadman, W. E. (1993). Characteristics of male elementary teachers in the U.S.A., at Teacher Education Program entry and exit. Teaching and Teacher Education: An International Journal of Research and Studies, 12(2), 197-210.

Cameron, M., Grudnoff, L., Gwilliam, M., \& Peddie, R. (1990). Finding your first job: From college to classroom under new rules. set, No. 2, Item 12.
Cameron, M., \& Gru[n]dnoff, L. (1992). From College to ...?: Asking New Zealand principals, 2 years on, about the new system of hiring beginning teachers. set, No. 2, Item 15.

Cameron, M., \& Grudnoff, L. (1993). What principals think of their beginning teachers. set, No. 2, Item 15.

Chambers, G. N., \& Roper, T. (2000). Why students withdraw from initial teacher training. Journal of Education for Teaching, 26(1), 25-43.

Clark, M., \& Vere-Jones, D. (1987). Science education in New Zealand: Present facts and future problems. Wellington: Royal Society of New Zealand.

Corkery, G. (2001). Men in primary teaching: A study of a cohort at Dunedin College of Education. Unpublished MPhil thesis, Massey University, Palmerston North.

Crooks, T., \& Flockton, L. (2000a). Aspects of technology: Assessmentresults 2000. National Education Monitoring Report 18. Dunedin: Educational Assessment Research Unit.

Crooks, T., \& Flockton, L. (2000b). Music: Assessment results 2000. National Education Monitoring Report 17. Dunedin: Educational Assessment Research Unit.

Crooks, T., \& Flockton, L. (2000c). Reading and speaking: Assessment results 2000. National Education Monitoring Report 19. Dunedin: Educational Assessment Research Unit.

Crooks, T., \& Flockton, L. (2001a). Information skills: Assessment results 2001. National Education Monitoring Report 21. Dunedin: Educational Assessment Research Unit.

Crooks, T., \& Flockton, L. (2001b). Mathematics: Assessment results 2001. National Education Monitoring Report 23. Dunedin: Educational Assessment Research Unit.

Crooks, T., \& Flockton, L. (2001c). Social studies: Assessment results 2001. National Education Monitoring Report 22. Dunedin: Educational Assessment Research Unit.

Cushman, P. (1998). The lack of male teachers in primary schools: Some issues raised by first year attrition rates at a College of Education. New Zealand Journal of Educational Administration, 13, 53-57.

Cushman, P. (1999). Male teachers' attitudes towards primary school teaching. Delta, 51(2), 71-89. 
Cushman, P. (2000). Research Note: Year 13 male students' attitudes to primary school teaching as a career. New Zealand Journal of Educational Studies, 35(2), 223-230.

Darling-Hammond, L., \& Sclan, E. M. (1996). Who teaches and why: Dilemmas of building a profession for twenty-first century schools. In J. Sikula (Ed.) Handbook of Research on Teacher Education (pp. 67101). A project of the Association of Teacher Educators. New York: Macmillan.

Education Review Office. (1999a). Pre-employment training for school teachers. Wellington: ERO.

<www.ero.govt.nz/Publications/eers1999/Prett>

Education Review Office. (1999b). The achievement of boys. Wellington: ERO. <www.ero.govt.nz/Publications/eers1999/Boys>

Farquhar, S-E. (1998). Teaching: A woman-only profession? New Zealand Annual Review of Education, 7, 169-180.

Garden, R. A. (Ed.) (1997). Mathematics and science performance in middle primary school: Results from New Zealand's participation in the Third International Mathematics and Science Study (TIMMS). Wellington: Ministry of Education, Research and International Section.

Hawe, E., Tuck, B., Manthei, R., Adair, V., \& Moore, D. (2000). Job satisfaction and stress in New Zealand primary teachers. New Zealand Journal of Educational Studies, 35(2), 193-205.

Livingstone, I. D. (1994). The workloads of primary school teachers: A Wellington region survey. Wellington: Chartwell Consultants.

Livingstone, I. D. (1999). The workloads of primary teaching principals: A New Zealand survey. Wellington: Chartwell Consultants.

McLoughlin, D. (1997, August). To be male is to beware. North and South, pp. 38-51.

Manthei, R. J., Gilmore, A., Tuck, B. F., \& Adair. V. (1996). Teacher stress in intermediate schools. Educational Research, 38, 3-19.

Ministry of Education. (1998). Education Statistics of New Zealand 1998. Wellington: Ministry of Education.

Murphy, P. F., \& Gipps, V. (Eds.) (1996). Equity in the classroom: Towards effective pedagogy for girls and boys. London: Falmer Press.

Nicholl, K., \& Totoro, V. (1992). The selection and recruitment of teacher trainees for 1992. Bulletin No. 6: Wellington: Ministry of Education, Research and Statistics Division.
Organisation for Economic Co-operation and Development (OECD). (2001). Education at a Glance OECD Indicators - 2001 edition $<$ www1.oecd.org/els/education/ei/eag/>

Renwick, M. (1993). Innovation in Teacher Education. Wellington: New Zealand Council for Educational Research.

Renwick, M., \& Vize, J. (1990). Windows on teacher education: Phase 1 Initiation into teacher education. Wellington: New Zealand Council for Educational Research.

Renwick, M., \& Vize, J. (1991). Windows on teacher education: Phase 2 - The second year. Wellington: New Zealand Council for Educational Research.

Renwick, M., \& Vize, J. (1992). Windows on teacher education: Phase 3 - The third year. Wellington: New Zealand Council for Educational Research.

Renwick, M., \& Vize, J. (1993a). Windows on teacher education: Phase 4 The first year in the classroom. Wellington: New Zealand Council for Educational Research.

Renwick, M., \& Vize, J. (1993b). Windows on teacher education: The final report. Wellington: New Zealand Council for Educational Research.

Trembath, V. (2000). Leaving early from initial teacher education: A case study. Unpublished MEd thesis, Auckland College of Education, Auckland.

\section{Acknowledgements}

I should like to express my sincere appreciation to Noeline Alcorn, Robyn Baker, John Dickie, Mark Sheehan and Ivan Snook for their many helpful comments on an early draft of this manuscript.

\section{The author}

Ian Livingstone is a former Director of the New Zealand Council for Educational Research, currently a visiting lecturer at the Victoria University of Wellington, and an independent educational consultant. He has edited and produced the New Zealand Annual Review of Education since 1996. His particular research interests lie in assessment, mathematics education, adult education, and programme evaluation; more recently he has branched out into teacher education, and the evaluation of early childhood education and family support and development initiatives. 